\title{
BMJ Global Health Pursuing health systems strengthening through disease-specific programme grants: experiences in Tanzania and Sierra Leone
}

To cite: Hemingway CD, Bella Jalloh M, Silumbe R, et al. Pursuing health systems strengthening through diseasespecific programme grants: experiences in Tanzania and Sierra Leone. BMJ Global Health 2021;6:e006615. doi:10.1136/ bmjgh-2021-006615

Handling editor Stephanie M Topp

Received 14 June 2021 Accepted 10 September 2021

Check for updates

(C) Author(s) (or their employer(s)) 2021. Re-use permitted under CC BY-NC. No commercial re-use. See rights and permissions. Published by BMJ.

${ }^{1}$ Department of International Public Health, Liverpool School of Tropical Medicine, Liverpool, UK

${ }^{2}$ University of Sierra Leone College of Medicine and Allied Health Sciences, Freetown, Sierra Leone

${ }^{3}$ Nuffield Department of Medicine, University of Oxford, Oxford, UK

${ }^{4}$ Malaria Program, Clinton Health Access Initiative, Dar es Salaam, Tanzania

${ }^{5}$ Clinton Health Access Initiative, Dar es Salaam, Tanzania

${ }^{6}$ National Malaria Control Program, Dodoma, Tanzania, United Republic of

Correspondence to

Dr Justin Pulford

Justin.Pulford@Istmed.ac.uk

\section{ABSTRACT}

Introduction Disease-specific 'vertical' programmes and health system strengthening (HSS) 'horizontal' programmes are not mutually exclusive; programmes may be implemented with the dual objectives of achieving both disease-specific and broader HSS outcomes. However, there remains an ongoing need for research into how dual objective programmes are operationalised for optimum results.

Methods A qualitative study encompassing four grantee programmes from two partner countries, Tanzania and Sierra Leone, in the Comic Relief and GlaxoSmithKline 'Fighting Malaria, Improving Health' partnership. Purposive sampling maximised variation in terms of geographical location, programme aims and activities, grantee type and operational sector. Data were collected via semi-structured interviews. Data analysis was informed by a general inductive approach. Results 51 interviews were conducted across the four grantees. Grantee organisations structured and operated their respective projects in a manner generally supportive of HSS objectives. This was revealed through commonalities identified across the four grantee organisations in terms of their respective approach to achieving their HSS objectives, and experienced tensions in pursuit of these objectives. Commonalities included: (1) using short-term funding for long-term initiatives; (2) benefits of being embedded in the local health system; (3) donor flexibility to enable grantee responsiveness; (4) the need for modest expectations; and (5) the importance of micro-innovation.

Conclusion Health systems strengthening may be pursued through disease-specific programme grants; however, the respective practice of both the funder and grantee organisation appears to be a key influence on whether HSS will be realised as well as the overall extent of HSS possible.

\section{INTRODUCTION}

External investment through both government and non-government funding bodies in national disease-specific programmes has been widely practiced within the global health sector, often with substantial population health impact. ${ }^{1-4}$ However, so called 'vertical' programme investment has been

\section{Key questions}

What is already known?

- External investment in disease-specific programmes has been widely practiced within the global health sector, often with substantial population health impact.

- So called 'vertical' programme investment has been critiqued on the basis that gains achieved may be unsustainable in the absence of broader health systems strengthening (HSS) or, in some cases, may have been achieved at the expense of the broade health system.

- Dual objective programmes that aim to address both a specific disease and strengthen the broader health system are increasingly favoured because of this criticism.

What are the new findings?

- This qualitative study highlights five common approaches and experiences that may support the pursuit of HSS objectives within the scope of a disease-specific programme grant.

- Using short-term grants (2-3 years) to support longterm initiatives ( $10+$ years).

- Delivery of project activities by partners embedded (or committed to embedding) within the local health system, that are responsive to local needs and HSS opportunities.

- Donor flexibility enabling grantee responsiveness.

- Using micro-innovation.

- Holding modest expectations of what level of HSS is achievable within often short-term programme time frames.

critiqued on the basis that gains achieved may be unsustainable in the absence of broader health systems strengthening (HSS) or, in some cases, may have been achieved at the expense of the broader health system. ${ }^{5}$ This critique of vertical programme investment has contributed to a growth in 'horizontal' 


\section{Key questions}

What do the new findings imply?

- Both external funders and grantee organisations play a key role in supporting HSS gain through disease-specific grants;

- through empowering trusted, embedded implementing partners to seek out and exploit HSS opportunities that present within the context of project delivery;

- and though fostering and resourcing an environment which enables partners to proactively and positively respond to HSS opportunities that can be reasonably accommodated.

programmes that aim to strengthen national health systems, providing the conditions necessary for effective and sustainable population health impact to be realised. ${ }^{67}$ Disease-specific vertical programmes and HSS horizontal programmes are not mutually exclusive; both continue to be supported in the global health sector and programmes may be implemented with the dual objectives of achieving disease-specific and broader HSS outcomes. Indeed, HSS interventions have been defined as system-level interventions that directly target one or more of the WHO's six health system building blocks ((1) service delivery, (2) health workforce, (3) health information systems, (4) access to essential medicines, (5) financing and (6) leadership/governance)) or disease-specific interventions or programmes that have important system-wide effects. ${ }^{8}$

How effective dual objective programmes have been, in terms of strengthening both the underlying health system and disease-specific programmes, remains somewhat uncertain. The purported HSS activities of many global health partners have been challenged on the grounds that they are not 'systems strengthening' as commonly defined, but rather unsustainable interventions primarily designed to ensure delivery of priority vertical programmes. ${ }^{9}{ }^{10}$ An early review exploring the interactions between global health partners, the disease-specific programmes they support, and broader HSS highlighted the need for robust and standardised outcome and impact assessment. ${ }^{4}$ However, few examples of HSS evaluation that allow a wide and robust assessment of an intervention's impact on a health system have subsequently emerged. ${ }^{811} 12$ Those studies that have examined the interaction between disease-specific programmes and the broader health system continue to report mixed results, with evidence of both positive and negative impact. ${ }^{13-16}$ Thus, there remains an ongoing need for research into how dual objective programmes may best be operationalised to support both disease-specific and broader HSS objectives.

This qualitative case study explores the experience of four organisations tasked with supporting HSS within the frame of a disease-specific programme grant; namely, the Comic Relief/GlaxoSmithKline 'Fighting Malaria, Improving Health' (FMIH) initiative. ${ }^{17}$ The primary study objective was to identify approaches to, and inherent tensions in, pursuing dual disease-specific and HSS objectives within the context of a relatively short-term (2-3years) project grant. The secondary study objective was to explore perceived HSS contributions, as reported by the four FMIH grantee organisations and their respective stakeholders, and their apparent fit across the six health system building blocks defined by the WHO. ${ }^{18} \mathrm{In}$ the absence of an objective outcome assessment (which was beyond the scope of this study), this component of our study affords a clearer picture as to the activities grantee organisations were working towards in pursuit of their HSS objectives and to what extent these activities align with a recognised HSS framework. Drawing on the study findings, which reveal commonalities in approach and experienced tensions in pursuit of recognisable (although unsubstantiated) HSS outcomes, we then propose an implementation model that may enhance the potential of disease-specific programme grants to facilitate HSS in low-income and middle-income country contexts. This model should remain hypothetical until such time as it can be tested within the context of a dualobjective programme with proven HSS outcomes.

\section{METHODOLOGY}

A qualitative study encompassing four grantee programmes from across two partner countries. Data were collected via semi-structured interviews (SSIs).

\section{Study setting}

Comic Relief (CR) and GlaxoSmithKline (GSK) formed a 5-year (2016-2021) strategic partnership to combat malaria and strengthen healthcare systems in Ghana, Mozambique, Sierra Leone, Tanzania and the Mekong subregion. Known as the 'Fighting Malaria, Improving Health' (FMIH) partnership, the programme awarded 23 grants worth a total of $£ 16.7$ million to local nongovernment organisations (NGOs), and international development partners working within the partnership countries. Specifically, the partnership aimed to: improve health outcomes for people living in the partnership's focus countries; strengthen health systems for tackling malaria in the partnership's focus countries; and inspire global action against malaria by telling compelling stories that demonstrate need and impact. The 23 grants, made and managed by CR, all variously supported one or more of three intervention 'pillars': (1) improving the quality of health services for communities affected by malaria; (2) increasing demand for health services by communities affected by malaria; and (3) improving malaria surveillance and information systems at local and national levels (a fourth pillar 'improving awareness of malaria' was also included, although this was not HSS-focused). These three intervention pillars were informed by a consultative prioritisation exercise undertaken in each partner country prior to the formulation of the grant call. The FMIH partnership's explicit focus on 'strengthening health systems for tackling malaria' positioned this funding scheme as an ideal candidate to explore grantee 
experiences of attempting to facilitate HSS within a disease-specific grant as did the partnerships commitment to research-based learning. Tetra Tech (formerly Coffey International) was contracted by CR to support the monitoring, evaluation and learning dimension of the partnership across all focus countries. The study described in this paper, subcontracted to the Liverpool School of Tropical Medicine, was one component of the partnerships wider learning programme. Further information about the FMIH programme, including the HSS objectives, intervention pillars and grantee programmes (including the four described below) can be found at: https://fightingmalariacouk/.

\section{Defining health system strengthening}

Grantees were not required by the programme funder to report against a defined set of HSS interventions and objectives. Similarly, the study team did not require participants to report against a specific definition of what constitutes a HSS outcome as opposed to what constitutes a disease-specific programme outcome. Rather, study participants were free to self-report what they considered to be the HSS interventions and outcomes of their respective projects as well as the factors they considered important to achieving these contributions. This decision, in part, reflects the ongoing debate about what may or may not represent a HSS versus disease-specific programme intervention ${ }^{19}$ but, more importantly, allowed us to explore participant interpretations of the HSS concept. Given the absence of a defined assessment of HSS outcome, the study findings should not be considered an objective account of the HSS contribution of grantee projects, nor should the study be considered a programme evaluation. Rather, the study findings are more appropriately considered a qualitative account of the perceptions and common experiences of a disparate group of grantees working towards a common, yet largely undefined, goal of supporting HSS within a diseasespecific programme context.

\section{Sample selection}

Given operational considerations, a decision was made at the outset to limit data collection to 4 out of 23 grantees from two out of the five partner countries/regions. A purposive sampling strategy was employed at both country and grantee level, with the aim of maximising variation in terms of geographical location, intervention pillar (across the three as described above), programme activities (nil/minimal overlap between grantees), grantee type (local or international NGO) and operational sector (public, private). Sierra Leone and Tanzania were subsequently selected as the two 'focal' countries as their respective grantee programmes have been running the longest (ie, there has been greater opportunity for health systems impact in these two countries as compared with other partner countries). From a total of 11 grantee programmes in Sierra Leone (7) and Tanzania (4), two grantees were selected from each country. These included the: Kings College Global Health Partnership (KGHP); Health Poverty Action (HPA), Sierra Leone; the Tanzania Communication and Development Centre (TCDC); and Clinton Health Access Initiative (CHAI), Tanzania. HPA and CHAI are international NGOs with established national offices, TCDC is a national NGO and KGHP is a partnership established in 2013 between Kings College London (UK) and Connaught Hospital (Sierra Leone), College of Medicine and Allied Health Sciences, University of Sierra Leone and the Ministry of Health and Sanitation (Sierra Leone).

KGHP focused on strengthening management pathways for patients with fever within Sierra Leone's largest referral hospital. HPA sought to improve access to malaria care for people who do not use services by (among other things) increasing awareness of the importance of seeking care and by training community-based health workers to treat malaria in the community. TCDC employed behaviour change communication approaches within target communities to promote prompt health seeking for febrile illness, adherence to recommended malaria tests and treatment and use of insecticide treated bed nets and intermittent preventive therapy (for pregnant women). CHAI primarily sought to strengthen the capacity of private drug shop dispensers (Accredited Drug Dispensing Outlets or 'ADDOs') in selected districts to diagnose, treat and report malaria, diarrhoea and pneumonia.

\section{Procedures}

Data collection took place in June 2019 (Sierra Leone) and August 2020 (Tanzania) at mid-stage and late-stage periods of programme implementation, respectively. Approval was first sought from the director of each case grantee organisation. This was facilitated by the provision of an information sheet describing the study, inviting further dialogue and clearly stating that participation was voluntary and at the discretion of each organisation. Once approval was obtained from the respective directors, the lead author $(\mathrm{CDH})$ liaised directly with a nominated programme representative to identify potential participants and to organise dates and logistics for site visits. Approximately 15 SSIs were purposively selected per case, ensuring a mix of staff directly involved in delivering the CR/GSK grant-funded project, key project partners or stakeholders and representatives of each projects' primary target audience (eg, ADDOs, community members).

Data collection was led by the lead author $(\mathrm{CDH})$ in collaboration with an in-country investigator (MBJ, Sierra Leone and RS, Tanzania) and under supervision of the last author (JP). All SSIs took place onsite at multiple programme delivery locations, were conducted over a 1-week period for each case and variously focused on (depending on who the interviewee was): project understanding, role and experience; project team structure; perceived project outcomes and impact; pathways to outcome/impact; sustainability; and collaboration and 
networking. Both positive and negative consequences of employing a disease-specific approach on HSS were probed during the interview.

Interviews were conducted using predeveloped interview guides in either English, Krio (Sierra Leone) or Swahili (Tanzania) as required. All interviews were conducted by two research team members, one leading the interview and the other taking notes. All interviews followed the principle of informed consent, were audio recorded and lasted approximately $60 \mathrm{~min}$ on average. Interviews were transcribed and when required translated into English. Audio files were deleted following transcription.

\section{Data analysis}

Data analysis was informed by a general inductive approach, ${ }^{20}$ aligning emerging themes identified in the data with predetermined focal areas relevant to the overarching study objectives. Interview transcripts were initially coded by the lead author $(\mathrm{CDH})$, resulting in a data framework and draft narrative presenting emerging themes and subthemes under constructs of 'HSS evidence' and 'HSS facilitators' informed by the literature. ${ }^{21}$ Perceived HSS contributions from the data were mapped to the six WHO health systems building blocks ${ }^{18}$ to reflect on areas where HSS was encountered within a defined health system and its boundaries. The framework and draft narrative were then shared with in-country investigators involved in data collection (MBJ and RS) and the principal investigator (JP) for critical review and collectively revised over three iterations. Final coding decisions as well as the content of the proposed implementation model were all agreed by consensus opinion. NVivo software (V.12) was used to support the data analysis.

Written informed consent was obtained from all study participants.

\section{Patient and public involvement}

No patients or members of the public were involved in the design, conduct or reporting of this study.

\section{RESULTS}

Sample

A total of 51 interviews were conducted across the four grantees; 30 in Sierra Leone (20 men and 10 women), 21 in Tanzania ( 15 men and 6 women). Table 1 summarises the total number of participants per grantee with a breakdown by participant role. National government workers were questioned on both in-country grantees. The difference in sample size between the different projects was predominantly due to the varying size of the project teams.

\section{Perceived health systems strengthening contributions}

Participants perceived a number of HSS contributions that potentially correspond to one or more of the health system building blocks as defined by WHO. Beginning

\begin{tabular}{|c|c|}
\hline $\begin{array}{l}\text { Grantee/national government } \\
\text { organisation }\end{array}$ & $\begin{array}{l}\text { No. of } \\
\text { participants }\end{array}$ \\
\hline $\begin{array}{l}\text { Kings College Global Health Partnership } \\
\text { (total) }\end{array}$ & 12 \\
\hline Grantee staff & 4 \\
\hline Volunteer overseas health professionals & 3 \\
\hline Local health workers & 5 \\
\hline Health Poverty Action (total) & 16 \\
\hline Grantee staff & 9 \\
\hline Local health workers & 2 \\
\hline District government workers & 2 \\
\hline Partner non-government organisation staff & 3 \\
\hline $\begin{array}{l}\text { Sierra Leone National Malaria Control } \\
\text { Programme (NMCP) }\end{array}$ & 2 \\
\hline $\begin{array}{l}\text { Tanzania Communication and Development } \\
\text { Centre (total) }\end{array}$ & 7 \\
\hline Grantee staff & 2 \\
\hline Regional/district government workers & 3 \\
\hline Local health workers & 2 \\
\hline Clinton Health Access Initiative (total) & 9 \\
\hline Grantee staff & 1 \\
\hline Regional/district government workers & 4 \\
\hline Local health workers & 4 \\
\hline Tanzania NMCP & 2 \\
\hline $\begin{array}{l}\text { Tanzania presidents office, regional } \\
\text { administration and local government }\end{array}$ & 3 \\
\hline
\end{tabular}

with 'access to essential medicines' (WHO Building Block 4 ), as grantees across all four cases were reliant on the national supply of malaria commodities to achieve the targeted objectives of their project, then efforts to address weaknesses in the local medical supply chain, including both short-term and long-term solutions were frequently reported. Long-term solutions involved working with local stakeholders to alter the ordering process, enhancing the efficiency and reducing the risk of supply shortages. Short-term solutions involved the provision of project vehicles to collect supplies during disputes. Local stakeholders perceived positive effects through efforts to improve the supply of malaria commodities, such as fewer stock outs, but also recognised that these efforts were an ongoing process:

We've still been working on it trying to see with the program [KGHP] how we can simplify the ordering process to ensure that when the orders are put, at least not more than 72 hours for us to receive the commodity. We're making progress but still some challenges along that line.-Physician, Sierra Leone

Relating to the supply of medical commodities which requires accurate and timely data to ensure supply meets demand, grantees reported interventions targeting 
'health information systems' (WHO Building Block 3). Two of the grantees (CHAI and HPA) reported efforts to strengthen the collection and use of malaria case data at the community and dispensary level, which by extension, influenced decision-making at the district level:

Another point about the positive outcome is ability for ADDOs now to submit reports [of malaria, pneumonia and diarrhoea cases treated or referred for inclusion in national health information system]. It's something that the region were missing, that case management from the drug shops so through the surveillance system they can be able to as a region to have a visibility to get that data from the $\mathrm{AD}$ DOs.-Government Worker, Tanzania

KGHP took a different approach and set out to strengthen health information systems through digitisation at the hospital level and consciously steered away from information systems specific to malaria. This was perceived to enable wider health system benefit as it supported the surveillance and monitoring of other health conditions.

Health workforce training (WHO Building Block 2) and mentorship was a frequently reported intervention, with all grantees reporting at least one form of health professional development across different levels of the health system; from refresher training for community health volunteers to training in febrile case management at the hospital level. While project activities maintained a malaria focus there was a strong will by local stakeholders to apply aspects of these initiatives to other health conditions. For example, febrile case management training implemented by KGHP by extension has supported management of other common conditions such as enteric fever, tuberculosis (TB) and HIV. In addition to health provider training, grantees also reported training efforts to improve supportive supervision by district health officials, which to a degree targets 'leadership/governance' (WHO Building Block 6). Participants also reported efforts beyond health workforce development to improve 'service delivery' (WHO Building Block 1), for example, KGHP, with support from the National Malaria Control Programme, were able to implement malaria rapid diagnostic tests (mRDTs) at the hospital which was reported to reduce the waiting time for patients to receive their results and access treatment. Interventions targeting 'financing' (WHO Building Block 5) were less evident from the data; however, there were reported initiatives aimed at sustaining financial incentives for community health volunteers beyond the lifetime of the project, for example, HPA were working on a village savings scheme.

A limitation of using the WHO health system building blocks to map the reported perceived HSS contributions are the divergent views on whether behaviour change interventions sit within the framework. While it can be argued that behaviour change interventions sit within service delivery (WHO Building Block 1), it has been acknowledged that the framework 'focuses on health sector actions and underplays the importance of actions in other sectors and does not take into account actions that influence peoples' behaviours, both in promoting and protecting health and the use of healthcare services. ${ }^{18}$, Two grantees (HPA and TCDC) delivered projects specifically designed to promote healthy behaviours and environments and increase acceptability and awareness of malaria diagnosis and treatment in the community. Participants from TCDC explained that while the project was focused on delivering malaria education and communication, the community change agents they were working with had been trained through previous projects to speak on HIV, family planning and TB, which meant that when they went out into the community under the FMIH grant, they were equipped to address a broad range of needs.

While many interventions deployed by grantees targeted one or more of the WHO health systems building blocks, most were primarily small scale and disease focused, achieved through close working partnerships with local stakeholders and ongoing access to health development funding.

\section{Common approaches and experiences in pursuing HSS objectives}

Five distinct themes emerged from across the data, each presented in turn below.

\section{Short-term funding for long-term initiatives}

Findings indicate that grantees were employing the relatively short-term FMIH grant (2-3 years) to support longer-term initiatives (eg, 10+ years). Grantees were cognisant that their interventions required ongoing technical assistance and external funding beyond the life of the project to be successfully maintained, embedded and scaled-up. Soft funding was treated by grantees as a means to an end, where in most cases the end was not achieved under the FMIH programme grant, but progress was made. In Tanzania, the idea to target ADDOs for the improvement of malaria case management at the primary level was first conceived and explored in 2012. A feasibility study conducted in 2014-2015 resulted in adoption of the ADDO programme by the Tanzania National Malaria Control Program (TNMCP). The 2017 FMIH programme grant was used to support the TNMCP in rolling out the ADDO programme nationwide. In 2020 , at the time of interview, government stakeholders reported a strong desire to sustain and expand the geographical and disease focus of the ADDO programme with the prerequisite of external funding:

At that primary stage we still have other diseases which can be also included [in the ADDO program], because now we are concentrating with the malaria and the rare pneumonia. But if you go further you can find that there is other diseases...I think it is very important to add those diseases especially some of those which are neglected tropical diseases... currently the government is actually supporting the program but partners are also supporting. We are sure that we cannot, actually it's the government, do it ourselves.-Government Worker, Tanzania 
Interviewees provided examples of ongoing nationwide roll out of the ADDO programme through support from other external donors and development partners. In addition, government pressure was being applied to the pharmacy council to expand the 6-week mandatory inception training for ADDOs to incorporate the management of fever focusing on malaria, diarrhoea and pneumonia as is currently provided by CHAI within the context of their grant. For TCDC, the FMIH funding enabled the continuation and geographical expansion of technical and financial support for social and behaviour change communication provided to the government since 2008.

In Sierra Leone, funding was used directly or indirectly for the continuation of a range of long-term HSS initiatives which began years before receipt of the FMIH programme grant, these included: training in case management at the tertiary level; increased access and improved management of ambulances at the district level; continuation of a health and well-being school education programme; improved management and use of hospital records; patient empowerment through employment of a patient advocate; and continuation of village development committees, empowering local communities to effectively advocate for better health services. HPA viewed the FMIH programme grant as an opportunity to sustain and expand on their maternal and child health work:

\begin{abstract}
...the Impact project [FMIH programme grant] from the design, it is an integrated project...We integrate malaria into an existing project which is more focused on maternal and child health. Most of the interventions in the Impact project were interventions that were ongoing in our maternal and child health project...It was like a complementary project.-HPA employee
\end{abstract}

\section{Embedded in the local health system}

Grantees in Sierra Leone and Tanzania represented organisations who were already embedded in the local health system, at the primary level (CHAI, TCDC and HPA) and tertiary level (KGHP). To a varying degree, grantees were known to and trusted by government health units and viewed as integral for the implementation of their strategic plans. From this position grantees were cognisant of the political and health system needs, capabilities and priorities and at the same time were influential in shaping them. Clear examples where the grantees collaborated with local health and government workers prior to applying for funding were evident in the data:

I was nominated by the Malaria Control Program to do some training in management of malaria in the tropics... When I came back, the Malaria Control Program manager informally acknowledge me to be a focal person for malaria at Connaught Hospital...Even before the SHIFT project [FMIH programme grant] start, I started looking into the way malaria patients are being treated and what are some of the challenges and all. That's how I came to know about KGHP and this comic relief. We put together the research projects and submitted, and we got this approval.-Physician, Sierra Leone

Local stakeholders valued these close relationships, viewing grantees as 'part and parcel' of their organisation, enabling them to establish a sense of ownership of grantee activities from the outset.

Understanding of government priorities and the landscape of development partner activities was obtained through informal social interactions and a range of formal partner and government forums. Grantees reported key benefits from engaging in these forums; from enabling them to collaborate with other partners working in their area enhancing the efficiency and scope of their work, to facilitating the incorporation of project activities into the local government work plans and budgets. When engagement in partner and government forums occurs after the receipt of grant money the flexibility of development partners to address government priorities and avoid duplication is constrained as they are contracted to meet the objectives set out in the funding proposal. While there were still reported imbalances in development partner support, both within the malaria response and for other health conditions, frequent interaction and the close working relationship between government bodies and grantees prior to the commencement of the FMIH programme grant mitigated against the risk of duplication and distortion.

They [TCDC] meet with the regional health management team (RHMT), they discuss the planning on how those activities [grantee activities] will be conducted. Maybe on a quarterly basis or monthly basis, depending on the need... So every partner will come with these plans... So among those activities which we have planned, those activities are discussed. Once they are discussed and we have agreed on each term that the activities will be conducted, and then some members of the RHMT, they have to supervise us during the implementation of such activities.-Government Worker, Tanzania

\section{Donor flexibility enabling grantee responsiveness}

The interviews demonstrated that how the donor operates was key to enabling grantees to pursue feasible and responsive HSS. Grantees commended the FMIH programme for their flexibility and support when project plans had to be adapted in response to evolving conditions and local priorities. For KGHP, this involved scaling back implementation of a hospital information management system to focus on the diagnostic laboratory; beginning with a closed system that could be expanded given greater time and resources, while ensuring impact was achieved under the grant by executing changes at a feasible scale for the hospital. For CHAI, unforeseen government pressure prevented the roll out of mRDTs to the ADDOs in 2017. Rather than lose time waiting for government approval CHAI was able to redirect efforts to improve malaria diagnostic services at private laboratories through roll out and training in mRDTs. 
Stated or tacit understanding by the grantees of donor flexibility enabled them to be responsive, to support other programmes and to do more where reasonable and with justification. Not only did this allow grantees to make changes to address difficulties but it also allowed them to work opportunistically to maximise impact. This understanding influenced grantee decisions during both project design and implementation. From HPA's approach, integrating the malaria project with their existing maternal and child health programme to facilitate the continuation and expansion of this work rather than proceed with a 'stand alone malaria intervention project'. To KGHPs approach to strengthening data systems, as illustrated by this quote:

\begin{abstract}
They were quite respectful of the need to strengthen data systems, not just let's have an electronic platform for malaria. Similarly, we said we want to do training on management of fever rather than on the management of malaria... yes, the funding is malaria focused but comes together in that context.-KGHP employee
\end{abstract}

Without this understanding grantees may have been reluctant to expand project activities beyond a malaria focus or respond to opportunities during the project.

\section{Modest expectations}

In contexts with seriously underfunded health systems, even if improvements can be achieved with targeted external support, they cannot easily be sustained after the period for which donor agencies are usually ready to commit funding. Grantees believed the donor was guilty of expecting too much from 2 to 3 year funding in terms of scale and sustainability of HSS activities, as illustrated by this quote:

One is that health systems reform is complicated and takes quite a long time to do it right. With hindsight, we were encouraged by Comic Relief that we would be unlikely to get the grant unless we were grandiose about the ideas that we were pitching. The potential of a national scale up and multi-disciplinarily and so on. I think it was right to do something that was quite broad. It was right to think of what could be the lessons that are transferable. One of the outputs from the project will be to have some toolkits that hospitals can use. I think we would have written a slightly less ambitious but more achieving, a more impactful proposal perhaps if we'd less felt less pressurized into doing so much.-KGHP employee

The quote above speaks to the notion that HSS may be best achieved through gradual, long-term application of a consistent approach. The need to demonstrate innovation and ambition in a project proposal can derail these 'slow and steady' approaches if they are not appealing enough to continuously attract funding.

For grantees focused on behaviour change interventions, there was the view that donor expectations for sustained impact on disease outcomes was unattainable given the nature of human behaviour and resource constraints preventing adoption of these activities by local government; resulting in resources being directed to interventions which had a more tangible and direct impact on health outcomes, as illustrated by this quote:

When it comes to behaviour change, usually it is a process, and most of the donors, most of the people, especially the government itself as well and other stakeholders, they have a lot of expectations. When it comes to when you are getting a fund, they want to get results...Sometimes, it's not easy to be able to measure the change, it is very challenging... And on the other side, the government has been putting more effort in when it comes to the tangible stuff, putting more money and support into equipment, health facilities, building more facilities, stuff like those. Getting them to focus on the soft things which they cannot touch like behaviour and education is somewhat also tricky and challenging.-TCDC employee

The participant noted that this issue was not unique to the FMIH programme.

\section{Micro-innovation}

While expectations of ambitious and highly innovative project proposals may not always support HSS, microinnovations appear essential. The focus of the grantees was not to introduce new service providers or products but to improve the quality and uptake of existing services though micro-innovation. This approach could be seen clearly in activities to sustain community health worker (CHW) motivation through financial incentives. Grantees in Sierra Leone and Tanzania were cognisant of limitations in CHWs relying on external funding to finance their community health work in the absence of adequate government support. To address this limitation, TCDC was piloting financial management training with CHWs and allocating small loans through communitybased organisations to enable CHWs to establish income generating activities. HPA reported intentions to support a village saving scheme in which the community would be responsible for paying the CHWs:

there is a village and saving loan scheme. It is very, very, very important... most of the projects that has been sustained today in Sierra Leone, those are the approaches they took...now, the narrative is changing. Even the communities, they want to do it themselves, sure. By the end of the project, if we have that scheme, I'm pretty sure that the impact will just resemble like the impact is still going on within a community.-HPA employee

Grantees also provided example of micro-innovation that were both simple to execute and easily sustainable which seemingly contributed towards health system strengthening. For example, to improve patient understanding of which services and commodities are free and which must be paid for, KGHP supported hospital management to post two large price lists at strategic points, in the entry point of accident and emergency and where payments are made. Transparent pricing improves patient access to health services and helps prevent fraudulent charges sometimes imposed by healthcare workers, thereby improving service quality. 


\section{DISCUSSION}

Participants reported wide ranging contributions towards HSS, many of which mapped onto the WHO's health systems building blocks such as the health workforce, health service delivery, health information systems and access to medicines. Some contributions were unequivocally health systems strengthening, such as improved National Health Information System data capture, whereas other reported contributions may have been more contentious in terms of whether they amounted to actual health system strengthening as opposed to disease specific health systems support. ${ }^{22}$ For example, most grantees supported supply chain strengthening in some capacity, arguably motivated by the need to ensure a reliable supply of malaria commodities to satisfy the demands of their respective malaria-control projects. Most of the reported HSS contributions were seemingly modest in scale and some, such as the provision of project vehicles to collect supplies, would be unsustainable once project support is removed further questioning their merit as a genuine HSS outcome. In this respect, the study findings mirror ongoing debates in the HSS literature pertaining to what is, and what is not, a HSS activity. The purported HSS activities of primarily disease-based programmes have been challenged on the grounds that they do not align with more widely recognised HSS frameworks as has the validity of so called 'spill over' effects in which activities undertaken in support of a disease-specific programme are said to have broader benefit across the health system. ${ }^{10} 23$ The reported HSS outcomes reported herein remain open to the same challenges.

Even if some perceived HSS contributions were overstated, the study findings suggest that grantee organisations structured and operated their respective projects in a manner generally supportive of HSS objectives. This is revealed through the commonalities identified across the four grantee organisations in terms of their respective approach to pursuing their HSS objectives, and experienced tensions in pursuit of these objectives. Commonalities included: (1) using short-term funding for long-term initiatives; (2) benefits of being embedded in the local health system; (3) donor flexibility to enable grantee responsiveness; (4) the need for modest expectations; and (5) the importance of micro-innovation. Of these five commonalities, a number were reflective of widely accepted principles of HSS such as meaningful collaboration with government partners from planning through to implementation, coordinating activities with other sector partners and ensuring sustainable funding and intervention strategies. ${ }^{424}$ Donor flexibility has previously been identified as an important factor in aid effectiveness, ${ }^{25}$ although arguably runs counter to prevailing notions of strict accountability in development funding expenditure and the prioritisation of targeted technical HSS intervention with clear and measurable outcomes. ${ }^{25} 26$ Our study findings suggest donor flexibility and grantee responsiveness in programme implementation, allowing HSS opportunities to be identified and accommodated, may be especially important HSS 'enabling' factors. This may be considered a form of 'bottom up' approach, in which organisations are empowered to 'self-organise' and develop context appropriate approaches based on their knowledge of local health systems. ${ }^{27}$ Embedded partners are perhaps best placed to operate in this way, although such licence to 'self-organise' should still be grounded within an evidence-based approach to decision-making. ${ }^{24}$

The modest nature and uncertain sustainability of many perceived HSS outcomes were perhaps indicative of the limited available time and resources within the FMIH project life spans. Actual health systems strengthening goes beyond investing in inputs; it requires reforming how the health system operates to ensure resilience and quality, and this cannot be achieved in a 2-3year period. ${ }^{28}$ Grantees sought to overcome these limitations to the benefit of the country by linking a series of short-term grants together. However, linking short-term grants requires a 'continuation' policy that is not always attractive to funders looking for innovation and attributable impact. Thus, funder support for the continuation, adaptation and/or scale up of proven, locally-embedded programmes may be central to HSS as is the realisation that outcomes during the course of any one grant may be modest and largely unattributable to a single source. Meanwhile, the onus remains on the programme implementers to regularly micro-innovate and, where necessary to ensure programme continuation, share resources and expertise with other actors in the local health system as has been argued, for example, in the context of development partner support for community health worker programmes. ${ }^{29}$ These findings further reveal the symbiotic relationship between donor and grantee in the pursuit of HSS outcomes: the donor provides the conducive environment in which a responsive grantee can support broader HSS objectives in their respective project settings. The less flexible the donor and/or the less responsive the grantee, the harder it may fully be to realise HSS objectives within the context of a primarily disease-specific grant. Findings from this study also suggest that the FMIH programme may have benefitted from providing grantees with a definition of HSS informed by the literature. Ambiguity in what constitutes HSS could dilute the term within the global health field, with grantees and donors promoting diseasespecific health system support as HSS. For example, ad hoc training of health workers was commonly practiced among grantees and was perceived as a HSS intervention, yet many would challenge this claim on the basis that national reform to the professional development standards would be required to constitute HSS.

Drawing on these study findings, figure 1 presents a hypothetical implementation model that may enhance the potential of disease-specific programme grants to facilitate HSS in low-income and middle-income country contexts. The model focuses on both donor and grantee actions, recognising the symbiotic relationship between the two. The model content is grounded solely within our 


\section{Grantee}

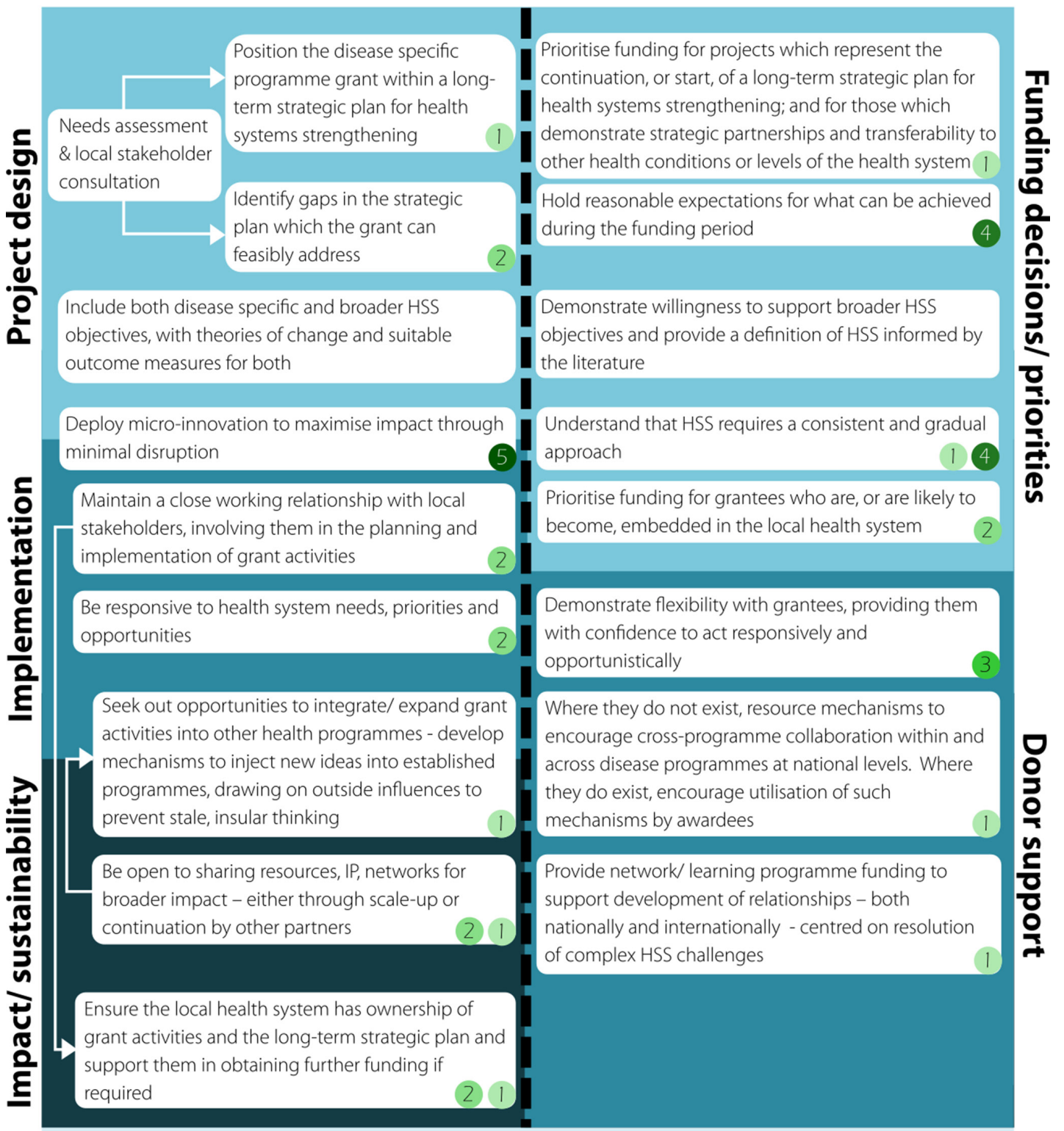

Figure legend to show how each recommendation relates to the 5 common factors:

1 Using short-term funding for long-term initiatives

2 Benefits of being embedded in the local health system

(3) Donor flexibility to enable grantee responsiveness

(4) The need for modest expectations

(5) The importance of micro-innovation

Figure 1 A hypothetical implementation model that may enhance the potential of disease-specific programme grants to facilitate health system strengthening (HSS) in low-income and middle-income country contexts.

study data and, as such, is not presented as a synthesis of (or alternative to) existing HSS frameworks or proven principles even though commonalities exist (as discussed above). In this respect the model may be considered the conceptual outcome of a qualitative research methodology akin to grounded theory approaches. ${ }^{30}$ The model presents actions hypothesised to be supportive of HSS from project design through to post implementation and sustainability. Actions on the left align with those on the right. From the grantee's perspective, actions supportive of HSS begin at project design, which involves working with local stakeholders and positioning the grant within a long-term strategic plan to formulate appropriate objectives and outcome measures. It requires considering what the grant can feasibly contribute to existing or new strategic plans with an understanding that short-term disease-specific grants are a means to make progress with additional funding required in the long-term. During 
implementation, the stated actions reiterate the need for gradual and responsive approaches and the importance of maintaining a close working relationship with local stakeholders during planning and implementation, which may enhance the sustainability of grant activities. The remaining actions highlight the potential benefits of cross-programme collaboration to support scale up and wider application of grant activities which requires openness and transparency. From the donor's perspective, the stated actions reiterate the importance of empowering embedded and trusted organisations, while holding reasonable expectations for HSS through shortterm grants and being supportive of gradual approaches and objectives which expand beyond the disease focus. The actions within 'donor support' highlight the need to foster and resource an environment in which grantees can effectively collaborate and act responsively.

The reported study was not without limitation. Only 4 out of the 23 FMIH grantees were included in the study as were only two out of the five participating countries/ regions. HSS experiences may have been different for other grantees in the same or other contexts and, as such, the reported findings should not be considered representative of the entire FMIH initiative. Data collection took place in June 2019 (Sierra Leone) and August 2020 (Tanzania) at mid-stage and late-stage periods of programme implementation, respectively; as such the level of impact and experience in HSS may have differed between the two focal countries. Having said that, the five identified commonalities were consistent across all four grantees included in the study suggesting some degree of generalisability. Certain terms used by interview participants did not have a direct English translation which, at times, led to ambiguity in the data during the translation process. To mitigate against the risk of misinterpretation, transcription and translation of interviews not conducted in English was carried out by MBJ and RS (fluent in Krio and Swahili, respectively). While perceived HSS contributions were reported and in some cases observed, the study did not seek to robustly measure the extent of HSS attained via grantee programmes; thus, it is not possible to infer the degree to which the reported 'common factors' did (or did not) contribute to HSS or the relative influence of each factor on HSS. It is for this reason that we present the subsequent implementation model as hypothetical. Further research will be needed to verify if the proposed model remains valid within the context of a disease-specific programme with proven HSS impact. The in-country investigator from Tanzania (RS) was also an employee of one of the case programmes (CHAI) raising the possibility of researcher-bias and/or participant-bias. To minimise the risk of the former, data analysis and reporting were conducted collaboratively and iteratively by four authors (CDH, MBJ, RS and JP) until consensus opinion was achieved. To reduce the risk of the latter, RS rarely sat in on participant interviews unless interpretation was needed in which case the provisions of participant confidentiality were clearly explained.

\section{CONCLUSION}

The experience of the four grantee organisations included in our qualitative study suggests HSS may be pursued through disease-specific programme grants; however, the respective practice of both the funder and programme implementers appears to be a key influence on whether HSS will be realised as well as the overall extent of HSS possible to achieve. Practices that enable continuation of proven programmes, delivered by partners embedded (or committed to embedding) within the local health system, that are responsive to local needs and HSS opportunities and that encourage micro-innovation may be especially powerful enablers of HSS within the context of a disease-specific programme grant; even more so if expectations of what level of HSS is achievable within often short-term programme time frames are realistically set. Our hypothesised HSS-supportive implementation model will need to be further tested in a diseasespecific programme with proven HSS impact.

Twitter Charlotte Devon Hemingway @CHemingway1990 and Mohamed Bella Jalloh@BellaJayMD

Contributors Study design and implementation was led by $\mathrm{CDH}$ under the supervision of the principal investigator JP. JP, CDH, MBJ and RS collaboratively collected the data, analysed the data and wrote the manuscript. MBJ and RS provided translation services and context expertise. HW, EM, SN and AL coordinated in-country ethical approval, supported recruitment and made a significant contribution to the data analysis and manuscript.

Funding This study was funded by Coffey International, GlaxoSmithKline and Comic Relief.

\section{Competing interests None declared.}

Patient and public involvement Patients and/or the public were not involved in the design, or conduct, or reporting, or dissemination plans of this research.

\section{Patient consent for publication Not applicable.}

Ethics approval This study was approved and granted ethical clearance from the Liverpool School of Tropical Medicine Research Ethics Committee (19-027), the Sierra Leone Ethics and Scientific Review Committee (expedited review, no ID provided. Approval letter dated 30 April 2019) and the Tanzanian National Institute for Medical Research (NIMR/HQ/R.8a/Vol.IX/3313).

Provenance and peer review Not commissioned; externally peer reviewed.

Data availability statement All data relevant to the study are included in the article or uploaded as supplementary information.

Open access This is an open access article distributed in accordance with the Creative Commons Attribution Non Commercial (CC BY-NC 4.0) license, which permits others to distribute, remix, adapt, build upon this work non-commercially, and license their derivative works on different terms, provided the original work is properly cited, appropriate credit is given, any changes made indicated, and the use is non-commercial. See: http://creativecommons.org/licenses/by-nc/4.0/.

\section{ORCID iDs}

Charlotte Devon Hemingway http://orcid.org/0000-0001-8993-3795

Mohamed Bella Jalloh http://orcid.org/0000-0002-3172-2749

Justin Pulford http://orcid.org/0000-0003-4756-8480

\section{REFERENCES}

1 The Global Fund. Result report 2019, 2020. Available: https://www. theglobalfund.org/media/8752/corporate_2019resultsreport_report en.pdf [Accessed Nov 30 2020].

2 Jaupart P, Dipple L, Dercon S. Has Gavi lived up to its promise? Quasi-experimental evidence on country immunisation rates and child mortality. BMJ Glob Health 2019;4:e001789. 
3 Jakubowski A, Stearns SC, Kruk ME, et al. The US president's malaria initiative and under-5 child mortality in sub-Saharan Africa: a difference-in-differences analysis. PLoS Med 2017;14:e1002319.

4 World Health Organization Maximizing Positive Synergies Collaborative Group, Samb B, Evans T, et al. An assessment of interactions between global health initiatives and country health systems. Lancet 2009;373:2137-69.

5 Biesma RG, Brugha R, Harmer A, et al. The effects of global health initiatives on country health systems: a review of the evidence from HIV/AIDS control. Health Policy Plan 2009;24:239-52.

6 Hafner T, Shiffman J. The emergence of global attention to health systems strengthening. Health Policy Plan 2013;28:41-50.

7 Warren AE, Wyss K, Shakarishvili G, et al. Global health Initiative investments and health systems strengthening: a content analysis of global fund investments. Global Health 2013:9:30.

8 Adam T, Hsu J, de Savigny D, et al. Evaluating health systems strengthening interventions in low-income and middle-income countries: are we asking the right questions? Health Policy Plan 2012;27 Suppl 4:iv9-19.

9 Marchal B, Cavalli A, Kegels G. Global health actors claim to support health system strengthening: is this reality or rhetoric? PLoS Med 2009;6:e1000059.

10 Tsai F-J, Lee H, Fan VY. Perspective and investments in health system strengthening of Gavi, the vaccine alliance: a content analysis of health system strengthening-specific funding. Int Health 2016;8:246-52.

11 Cleary S. Economic evaluation and health systems strengthening: a review of the literature. Health Policy Plan 2021;35:1413-23.

12 Fatodu OO, Oyenuga OO. Effectiveness of health systems strengthening interventions in Africa: a systematic review. IJHP 2019:1:52-69.

13 Rao KD, Ramani S, Hazarika I, et al. When do vertical programmes strengthen health systems? A comparative assessment of diseasespecific interventions in India. Health Policy Plan 2014:29:495-505.

14 Yu D, Souteyrand Y, Banda MA, et al. Investment in HIV/AIDS programs: does it help strengthen health systems in developing countries? Global Health 2008;4:8.

15 Burkot C, Gilbert K. Eliminating again, for the last time: a case study of donor support for malaria in Solomon Islands. Asia Pac Policy Stud 2021;28:320.

16 Doherty T, Besada D, Goga A, et al. "If donors woke up tomorrow and said we can't fund you, what would we do?" A health system dynamics analysis of implementation of PMTCT option B+ in Uganda. Global Health 2017;13:51.
17 Comic Relief, GlaxoSmithKlein. The Comic relief GSK partnership: driving progress towards universal health coverage, 2020. Available: https://wwwcomicreliefcom/sites/default/files/downloads/CRGSK\%20Booklet\%20VF2pdf

18 World Health Organization. Monitoring the building blocks of health systems: a Handbook of indicators and their measurement strategies. Geneva: WHO, 2010.

19 Shakarishvili G, Lansang MA, Mitta V, et al. Health systems strengthening: a common classification and framework for investment analysis. Health Policy Plan 2011;26:316-26.

20 Thomas DR. A general inductive approach for analyzing qualitative evaluation data. Am J Eval 2006;27:237-46.

21 Witter S, Palmer N, Balabanova D, et al. Health system strengthening-Reflections on its meaning, assessment, and our state of knowledge. Int J Health Plann Manage 2019;34:e1980-9.

22 Chee G, Pielemeier N, Lion A, et al. Why differentiating between health system support and health system strengthening is needed. Int J Health Plann Manage 2013;28:85-94.

23 Luboga SA, Stover B, Lim TW, et al. Did PEPFAR investments result in health system strengthening? A retrospective longitudinal study measuring non-HIV health service utilization at the district level. Health Policy Plan 2016;31:897-909.

24 Swanson RC, Bongiovanni A, Bradley E, et al. Toward a consensus on guiding principles for health systems strengthening. PLoS Med 2010;7:e1000385.

25 Gulrajani N. Organising for donor effectiveness: an analytical framework for improving aid effectiveness. Dev Policy Rev 2014;32:89-112.

26 Storeng KT. The GAVI Alliance and the 'Gates approach' to health system strengthening. Glob Public Health 2014;9:865-79.

27 Swanson RC, Atun R, Best A, et al. Strengthening health systems in low-income countries by enhancing organizational capacities and improving institutions. Global Health 2015;11:5.

28 Kruk ME, Gage AD, Arsenault C, et al. High-Quality health systems in the sustainable development goals era: time for a revolution. Lancet Glob Health 2018;6:e1196-252.

29 Cometto G, Ford N, Pfaffman-Zambruni J, et al. Health policy and system support to optimise community health worker programmes: an abridged who guideline. Lancet Glob Health 2018;6:e1397-404.

30 Strauss A, Corbin J. Grounded theory methodology: An overview. In: Denzin NK, Lincoln YS, Denzin N, et al, eds. Handbook of qualitative research. Thousand Oaks, CA: Sage Publications, Inc, 1994: 273-85. 